\title{
Design and Experiment Study of High Power Automobile Water Pump Based on CFD
}

\author{
Zhanlong Cao ${ }^{1, \mathrm{a}}$,Qunpo Zhang ${ }^{2}$ \\ ${ }^{1}$ School of Mechanical Engineering, Hubei University of Automotive Technology, Shiyan, China \\ ${ }^{2}$ Dongfeng Motor Pump Company Limited, Shiyan, China
}

\begin{abstract}
A high power automobile cooling water pump is designed and developed based on the theory of centrifugal pump design and computational fluid dynamics (CFD). The structure of the automobile cooling water pump adopts a curved guide rib structure, so as to avoid the dry friction of the automobile cooling water seal of the pump. The structural elements and flow field of the automobile cooling water pump assembly are optimized by simulation analysis. The peak efficiency of the automobile cooling water pump assembly is more than $51 \%$, the automobile cooling water pump performance has been significantly improved. The effective methods and means of product verification have been developed to ensure the high reliability and durability of the automobile cooling pump assembly.
\end{abstract}

\section{Introduction}

The working principle of an automobile engine is to promote the movement of the crankshaft through the compression and expansion of the gas. However, in this process, a lot of heat is harmful to the parts. Therefore, this part of the heat required to use the pump to pump cooling water away, this pump is the engine cooling water pump [1,2]. The cooling water pump is the key component of the engine cooling water system, and it is a kind of engine assembly with high reliability, stability and matching requirement. Its performance directly determines the operation of the engine. With the domestic and international heavy truck gradually to the heavy, high power development trend, the engine power will bring the necessary parts of the upgrade, at the same time high-power engine cooling water pump also need to be matched. Therefore, it is necessary to design a new type of cooling water pump which can meet the requirements of high power engine, high efficiency, high reliability and long life. The pump is designed to reduce the pump internal volume loss and hydraulic loss as the main target, considering the key pump between the key parameters of the flow components of the interdependence and restriction relations, take the "small range selection, optimization analysis method of fixed value" CFD simulation. The water pump is used to bend the reinforcement technology, at the same time; it has been a unique product verification methods and means.

\section{Design parameters of automobile water pump}

The pump is designed to apply the engine displacement is $13 \mathrm{~L}$, power range is $405.5 \sim 552.6$ metric horsepower. Pump performance index: Engine speed is $3702 \mathrm{rpm}$, pump flow is $3981 / \mathrm{min}$, and pump lift is not less than $19.7 \mathrm{~m}$, pump peak efficiency is more than $50 \%$, the service life is $1000000 \mathrm{~km}$ or 10 years, double SIC water seal is used, the reliability of the water seal is to provide evidence to prove, pump development process must be scientific.

\section{Overall parameters and structure design of automobile water pump}

The pump is designed based on the basic theory of centrifugal pump design. At the same time, the existing pump structure is referenced. After the calculation of the relevant parameters of the pump design, the final arc blade, the control blade inlet and outlet area ratio of 1.12 (The recommended value is 1.0 1.3) is selected. In order to effectively reduce the hydraulic loss of the pump, the hydraulic radius of the impeller is $24 \mathrm{~mm} * 23 \mathrm{~mm}$. In order to reduce the volume loss and the friction loss of the water in the pump, the outer diameter of the impeller D2 is reduced reasonably, the larger blade outlet angle 2 is selected, the impeller outlet width B2 and the volute throat area are increased. The pump is mainly composed of pump casing, pump shaft, seal, pump impeller, belt pulley, and pump cover. The specific structure is shown in Figure 1.

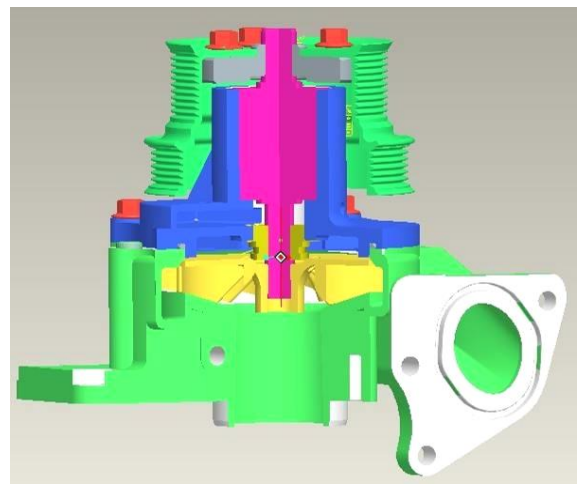

Fig1. Overall structure of automobile water pump

Corresponding author: caozl@mail.ustc.edu.cn 


\section{Design of automobile water pump}

\subsection{CFD optimization design}

Numerical analysis of flow field is one of the most widely used methods in pump design. Based on the theory of computational fluid dynamics (CFD), the flow field of the cooling water pump is analyzed by using the flow field analysis software, which can be used to predict the performance of the cooling water pump [3]. Performance results are obtained, which can optimize the pump.

The automobile cooling water pump assembly is optimized by using CFD technique $[4,5,6]$. Taking the cross section of the volute shell as an example, the overall optimization of the vortex shell is analyzed. The results show that the primary section of the vortex chamber is $1015 \mathrm{~mm} 2$ (mean section velocity $6.54 \mathrm{~m} / \mathrm{s}$ ) and the isobaric distribution in the volute is shown in figure 2 .

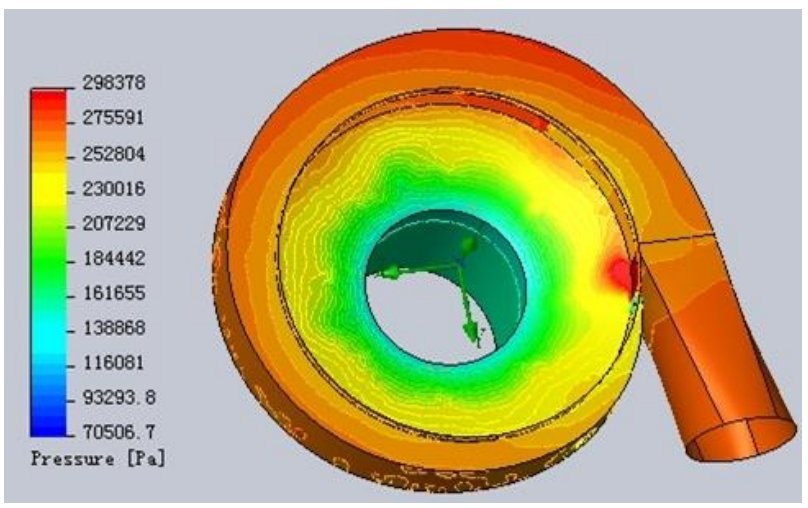

Fig2. Isobaric distribution in a vortex shell with a cross section of $1015 \mathrm{~mm} 2$

When the cross section is $1189 \mathrm{~mm} 2$ (mean section velocity $5.58 \mathrm{~m} / \mathrm{s}$ ), the isobaric distribution in the volute is shown in Figure 3.

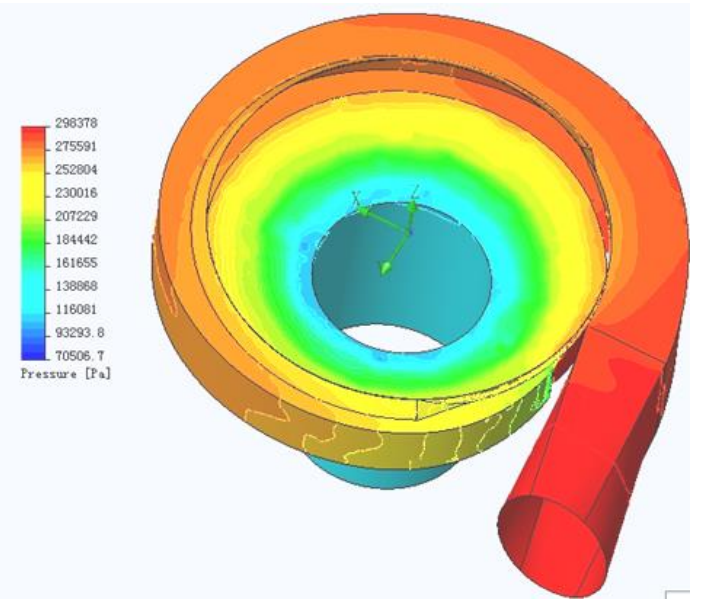

Fig3. Isobaric distribution in a vortex shell with a cross section of $1189 \mathrm{~mm} 2$

As can be seen from the chart, the section is 1189 $\mathrm{mm} 2$, the coolant flow from the vortex chamber starting end to the diffusion tube inlet section, the vortex distribution curve of indoor pressure gradually increased, change of uniform, fully illustrated the vortex chamber can be high energy liquid from the impeller flow fully into high potential and the required loss is small, and the formation of a pump required pressure in the pump outlet, the pump complies with the design requirements. Therefore, the cross section of the constituency is in line with the requirements, using a cross-section of 1189 $\mathrm{mm} 2$.

The pressure line final optimization of the pump assembly, as shown in Figure 4, it can be seen from the figure: pump internal flow from the pump inlet to the pump outlet uniform gradient, the pressure gradually increased, such as the pressure of hypertension did not appear abnormal trajectories, consistent with the operating characteristics of hydraulic.

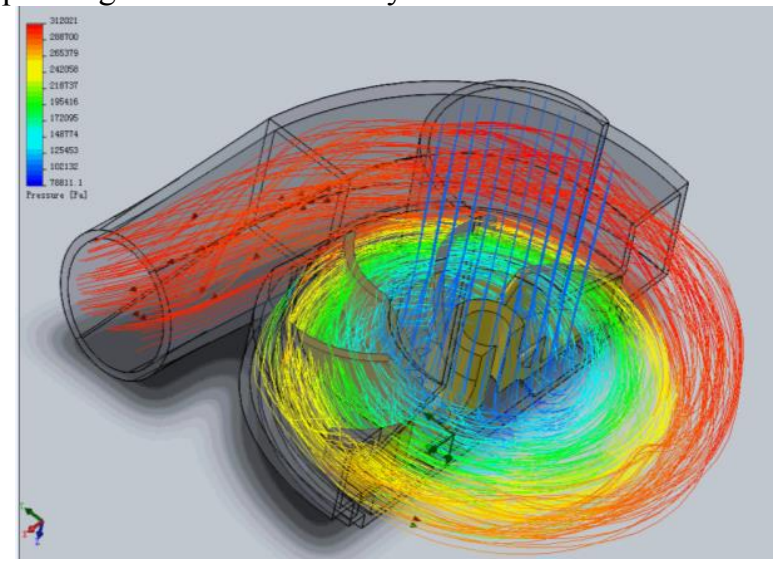

Fig4. Hydraulic trajectory of automobile cooling water pump optimization

\subsection{Selection of automobile water pump seal}

Water seal failure will directly lead to the failure of the automobile water pump, so the choice of water seal is very important. Therefore, specific "theoretical calculation test" unique selection mode, the selection mode not only solves the matching of the antifreeze liquid rust water seal and water pump assembly and use, but also to avoid the blindness of seal selection. 3 preliminary meet the requirements and technical maturity of the seal was analyzed: Eng40089 type seal for John Crane, and KACO $91470400(60 \mathrm{~N})$ and $93301000(45 \mathrm{~N})$, and to analyze the pump working environment as the basis, through the calculation of key parameters of water seal rigorous theoretical data, see table I. It can be seen that the 3 kinds of water seals are more balanced in the water seal and the back pressure coefficient $\lambda$, and the Eng40089 is more dominant in the balance coefficient $\beta$. While the two KACO seal by increasing the contact area of the effective movement ring also avoid the shortcomings in the area, and in the end the most important friction two side PV pressure $\mathrm{K}$ and end face seal 93301000 than the other two kinds of water sealing requirements to meet the national standard in the numerical values are more scattered and minimum, meet the pump assembly need. Therefore, the comprehensive performance of the KACO 93301000 type water seal is relatively good compared with other parameters, and the KACO 93301000 model water seal 
is tested. The test results show that it meets the requirements.

Table 1. Water seal calculation data

\begin{tabular}{|l|l|l|l|}
\hline Item/ Seal type & $\begin{array}{c}\text { Eng400 } \\
\mathbf{8 9}\end{array}$ & \multicolumn{1}{|c|}{$\mathbf{9 1 4 7 0 4 0 0}$} & $\mathbf{9 3 3 0 1 0 0 0}$ \\
\hline $\begin{array}{l}\text { Compliance of water } \\
\text { seal(time /min) }\end{array}$ & $\geq 8000$ & $\geq 8000$ & $\geq 8000$ \\
\hline $\begin{array}{l}\text { Equilibrium } \\
\text { coefficient } \beta\end{array}$ & 0.1837 & -0.0963 & -0.0963 \\
\hline $\begin{array}{l}\text { Back pressure } \\
\text { coefficient } \lambda\end{array}$ & 0.667 & 0.667 & 0.667 \\
\hline $\begin{array}{l}\text { Face specific pressure } \\
\text { K (Kpa) }\end{array}$ & $\begin{array}{l}982.8 \sim 1 \\
965.2\end{array}$ & $\begin{array}{l}1050.4 \sim 1530 . \\
5\end{array}$ & $\begin{array}{l}690.3 \sim 117 \\
0.4\end{array}$ \\
\hline $\begin{array}{l}\text { PV value of end face } \\
\text { friction pairs } \\
(\text { Kpa•m/s })\end{array}$ & $\begin{array}{l}4676.8 \sim \\
9351.6\end{array}$ & $\begin{array}{l}5654.8 \sim 8239 . \\
4\end{array}$ & $\begin{array}{l}3716.3 \sim 63 \\
00.9\end{array}$ \\
\hline
\end{tabular}

\subsection{Structural design of curved guide bar}

The water flow around the water seal is taken as the optimization objective, and it is optimized by three aspects, such as the velocity of water flow, the pressure of water flow and the increase of water flow rate, so as to increase the design of the structure of the curved guide bar, as shown in Figure 5. Through this design to ensure that the water seal around the pump flow stability, adequate, no cavitations' occurs.

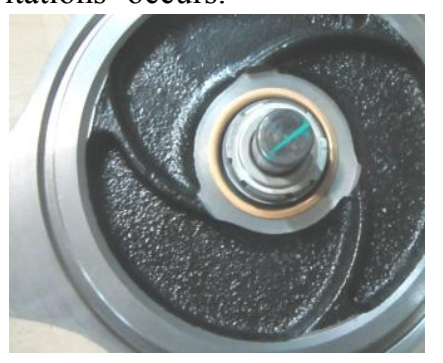

Fig5. Structure of curved guide bar

The flow path of the pump assembly is not optimized and the optimized flow path of the pump assembly is shown in Figure 6, Figure 7. After the flow trajectory (shown in yellow for the comparison can be seen through the impeller bottom), volute and impeller clearance and reach the water flow around the impeller bottom and water increased significantly, reaching the bottom water seal impeller optimization is expected to improve the surrounding water status.

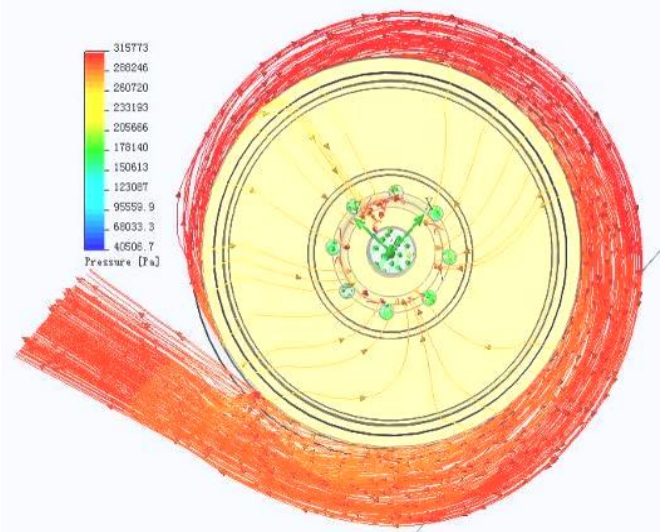

Fig6. The flow path of the pump assembly is not optimized

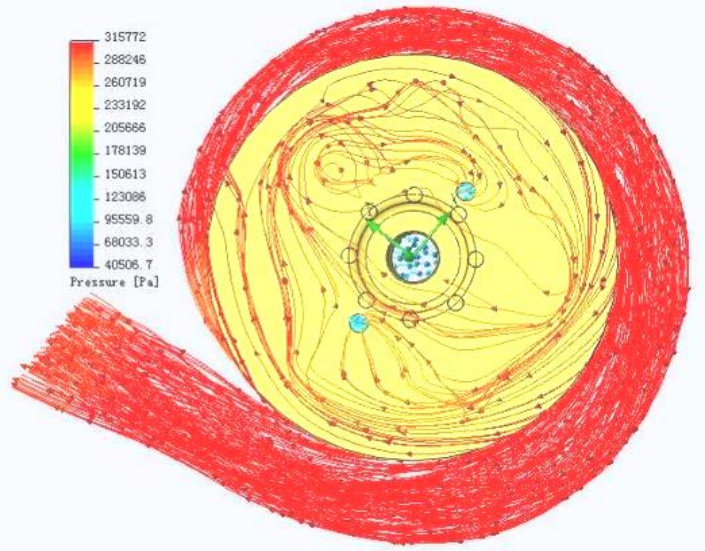

Fig7. The flow path of the pump assembly is optimized

\subsection{Design of automobile water pump life}

In order to ensure the reliability of the pump life, put aside the previous design method of the whole and part of the pump, update the design concept, and take the reliability of the overall matching of the pump as the research object. In the process of development in order to ensure the reliability of sealing and bearing life to meet the requirements on the basis of the pump cover two key parts installation hole shape and position tolerance and strict requirements, and select the appropriate seal assembly process and bearing, ensure the pump assembly to ensure matching, to ensure the high life, high pump reliability. For the selection of water seal and bearing, through the combination of theoretical calculation and experimental verification, select the two key parts suppliers and product types. The bearing according to the theoretical calculation for reliability coefficient was 0.21 and $99 \%$, according to the checking speed and stress value calculation, get life in different conditions of the engine under the bearing 21171.93 hours for the comprehensive life value in the pump rated speed, and meet the design life of the pump.

\subsection{Manufacturing and assembling technology of automobile water pump}

In order to ensure the high reliability of water pump assembly, in the assembly, also need to avoid ever in the assembly of the water seal, adversely affect the hidden failure of the bearing and housing, to ensure that key parts of the selection of the best use.

The bearings in the assembly process, there may be too much pressure on the pump cover a hidden cracks and other issues, bearing assembly with hot charging equipment, through high temperature heating rod of the bearing bore of bearing hole producing thermal expansion, and then directly to the bearing in the bearing hole, through natural cooling the bearing hole to eliminate the hard pressed and natural problems in the implementation process of the process, through a number of tests, and heating temperature on the pump cover shell are calibrated to avoid high temperature caused damage 
to the pump cover, as shown in Figure 8, the red circle as part of the pump cover.

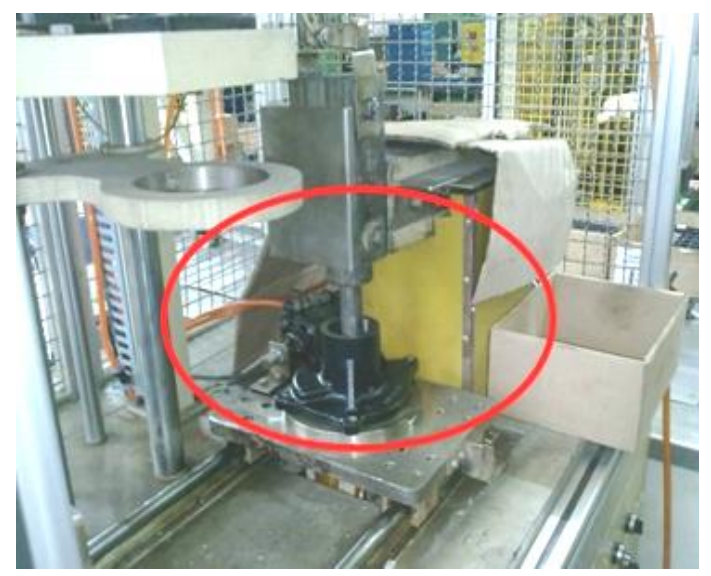

Fig8. Hot charging equipment for automobile water pump

Stealth fragmentation problems may arise in the process of pressing water, attached have been designed, the water seal flip directly with the pressing head contact, avoid pressing water when the pressure head mounted on the lower part of the water seal static ring momentum, as shown in Figure 9, the red circle section for the seal

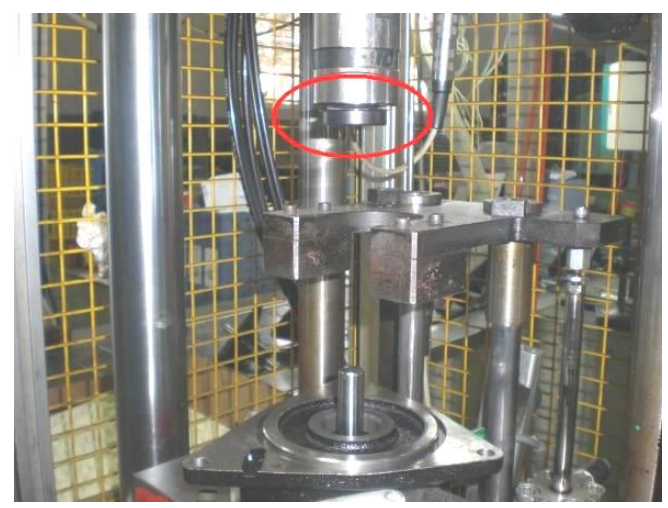

installation position.

Fig9. New water seal pressing method

Through the improvement of the above methods, there is no problem that the water pump cover is broken or the water seal leaks in the sealing test.

\section{Verification and experiment of automobile water pump}

The automobile water pump assembly needs to be subjected to the routine test $[7,8]$, and the GOC, Debris Coolant Test, water seal surface temperature test and torque destructive test should be carried out at the same time. Therefore the comprehensive performance of automobile water pump test bench was developed. The advanced comprehensive performance test rig, three test stations, all test automation, through the design of special together meet the full flow test to verify the vast various types of automobile water pump. The sealing performance test of 2 sets of automobile water pump is made by itself, which can meet the sealing test of automobile water pump.

Test medium: anti rust and anti rust liquid, temperature: : $90^{\circ} \mathrm{C} \pm 5^{\circ} \mathrm{C}$, inlet pressure greater than 0 Kpa.

The specific tests are as follows: leak-test, index point performance test, cavitations' test, evaporation test, Seal Face Temperature Measurement, reliability test. The experimental results show that the parameters of the automobile water pump are in line with the requirements, see Table 2.

Table 2. Experimental project and result of water pump

\begin{tabular}{|l|c|c|c|}
\hline \multicolumn{1}{|c|}{$\begin{array}{c}\text { Test } \\
\text { name }\end{array}$} & Test objective & Test requirements & $\begin{array}{c}\text { Test } \\
\text { resul } \\
\text { teak-test }\end{array}$ \\
\hline $\begin{array}{l}\text { Index } \\
\text { point } \\
\text { performan } \\
\text { ce test }\end{array}$ & $\begin{array}{c}\text { Performance } \\
\text { meets } \\
\text { requirements }\end{array}$ & $\begin{array}{c}\text { Leakage: cover } \\
\text { total: } 2.5 \mathrm{ml} / \mathrm{min} ; \\
\text { assembly: } 6 \mathrm{ml} / \mathrm{min}\end{array}$ & Pass \\
\hline $\begin{array}{l}\text { Cavitation } \\
\text { s' test }\end{array}$ & $\begin{array}{c}\text { Performance } \\
\text { point requirements } \\
\text { mequirements }\end{array}$ & $\begin{array}{c}\text { No cavitations' } \\
\text { occurs when } \\
\text { importing } 0 \mathrm{Kpa}\end{array}$ & Pass \\
\hline $\begin{array}{l}\text { Evaporati } \\
\text { on test }\end{array}$ & $\begin{array}{c}\text { Comprehensive } \\
\text { performance of } \\
\text { water seal }\end{array}$ & $\begin{array}{c}\text { No more than } \\
300 \mathrm{mg} / \mathrm{hr}\end{array}$ & Pass \\
\hline $\begin{array}{l}\text { Seal Face } \\
\text { Temperat } \\
\text { ure } \\
\text { Measurem } \\
\text { ent }\end{array}$ & $\begin{array}{c}\text { Matching of water } \\
\text { seal and assembly }\end{array}$ & $\begin{array}{c}\text { The difference } \\
\text { surface temperature } \\
\text { and the inlet } \\
\text { temperature is less } \\
\text { than } 6{ }^{\circ} \mathrm{C}\end{array}$ & Pass \\
\hline $\begin{array}{l}\text { Reliability } \\
\text { test }\end{array}$ & Reliability & $\begin{array}{c}\text { More than } 1000 \\
\text { hours }\end{array}$ & Pass \\
\hline
\end{tabular}

Automobile water pump was carried out a variety of different engine output speed performance test data are shown in Table 3. When the rated speed is $3072 \mathrm{rpm}$, the test data flow of the automobile water pump is displayed as $698.711 / \mathrm{min}$, the head is $19.85 \mathrm{~m}$, the peak efficiency is $51.03 \%$, and the hump phenomenon is not appeared. The performance indexes of automobile water pump have reached the design requirements.

Table 3. Test data of performance indexes of automobile water pump at different speeds

\begin{tabular}{|c|c|c|c|c|c|}
\hline $\begin{array}{c}\text { Speed } \\
\text { r/min }\end{array}$ & $\begin{array}{c}\text { Flow } \\
\text { l/min }\end{array}$ & Lift $\mathbf{m}$ & $\begin{array}{c}\text { Torque } \\
\mathbf{N}^{*} \mathbf{m}\end{array}$ & $\begin{array}{c}\text { Shaft } \\
\text { power } \\
\text { KW }\end{array}$ & $\begin{array}{c}\text { Peak } \\
\text { efficienc } \\
\mathbf{y} \%\end{array}$ \\
\hline 3455 & 780.82 & 24.91 & 16.61 & 6.01 & 51.44 \\
\hline 3072 & 698.71 & 19.85 & 13.46 & 4.33 & 51.03 \\
\hline 2685 & 603.01 & 15.33 & 10.51 & 2.96 & 49.97 \\
\hline 2304 & 510.98 & 11.53 & 8.01 & 1.93 & 48.43 \\
\hline
\end{tabular}

\section{Conclusions}

In accordance with the requirements of the relevant parameters, a high-power automobile water pump has been designed. When the water pump is designed, the key components are selected, the assembly process is 
improved, and the advanced simulation technology is applied to the integrated technology. The flexure type diversion technology was created for the first time. In order to improve the operation environment of water seal, the dry friction problem of high elastic water seal is solved. Unique product validation methods were carried out, the peak efficiency of the automotive water pump reached $51.03 \%$, its efficiency has been greatly improved. The design and development of the automobile cooling water pump product has been laid the foundation.

You are free to use colour illustrations for the online version of the proceedings but any print version will be printed in black and white unless special arrangements have been made with the conference organiser. Please check with the conference organiser whether or not this is the case. If the print version will be black and white only, you should check your figure captions carefully and remove any reference to colour in the illustration and text. In addition, some colour figures will degrade or suffer loss of information when converted to black and white, and this should be taken into account when preparing them.

\section{Acknowledgments}

This work was supported by Science and technology research project of Hubei Provincial Department of Education (B2017086).

\section{References}

[1] Shouqi Yuan,Tingting Zhang,Jinfeng Zhang,Jianrui Liu,Bing Pei, "Optimization design and test study on automobile cooling pumps," Journal of Drainage and Irrigation Machinery Engineering, vol. 32, pp. 93-96, February 2014.

[2] Jie Wu ,Qian TangG,Yuanxun Zhang ,Qixiang Fengi, "Impeller Design and Experiment for Automobile Water Pump Based on CFD," Mechanical Research and Application, vol. 26, pp. 89-91, February 2013.

[3] Jie $\mathrm{Wu}$ " "Flow field simulation and design of water pump for automobile cooling system," Chongqing University, pp. 34-60, April 2013.

[4] Fujun Wang, "The theory and application of computational fluid dynamics CFD software," Tsinghua university press, 2004.

[5] Dongping Shen,Hongbao Zhang,Ming Yang etc, "Application of CFD numerical simulation in automobile water pump product development," ANSYS.CFD proceedings of China, pp. 205-208, 2007.

[6] Voorde J V, Dick E, Vierendeels J, Serbruyns S, "Performance prediction of centrifugal pumps with steady and unsteady CFD," Advances in Fluid Mechanics, pp. 559-568, 2002.

[7] "Experimental method of cooling water pump for automobile engine," QC/T 288.2-2001.

[8] "Test method for performance of internal combustion engine cooling pumps," JB/T 8126.21999. 